Article

\title{
Contamination Pathways can Be Traced along the Poultry Processing Chain by Whole Genome Sequencing of Listeria innocua
}

\author{
Mayada Gwida ${ }^{1, \dagger}{ }^{,}$Stefanie Lüth ${ }^{2,3,+, *(\mathbb{D}}$, Maged El-Ashker ${ }^{4}\left(\mathbb{D}\right.$, Amira Zakaria ${ }^{5}$, \\ Fatma El-Gohary ${ }^{1}\left(\mathbb{D}\right.$, Mona Elsayed ${ }^{1}$, Sylvia Kleta ${ }^{2}$ and Sascha Al Dahouk ${ }^{2,6}{ }^{(D)}$ \\ 1 Department of Hygiene and Zoonoses, Faculty of Veterinary Medicine, Mansoura University, \\ Mansoura 35516, Egypt; mayada.gwida@gmail.com (M.G.); dr.fatmagohary@gmail.com (F.E.-G.); \\ dr.monamohy@yahoo.com (M.E.) \\ 2 Department of Biological Safety, German Federal Institute for Risk Assessment, Max-Dohrn-Straße 8-10, \\ 10589 Berlin, Germany; sylvia.kleta@bfr.bund.de (S.K.); Sascha.Al-Dahouk@gmx.de (S.A.D.) \\ 3 Institute for Biology, Freie Universität Berlin, Königin-Luise-Straße 1-3, 14195 Berlin, Germany \\ 4 Department of Internal Medicine, Infectious and Fish Diseases, Faculty of Veterinary Medicine, Mansoura \\ University, Mansoura 35516, Egypt; maged.elashker1978@gmail.com \\ 5 Department of Food Hygiene and Control, Faculty of Veterinary Medicine, Mansoura University, \\ Mansoura 35516, Egypt; amera.zakaria@yahoo.com \\ 6 RWTH Aachen University Hospital, Pauwelsstraße 30, 52074 Aachen, Germany \\ * Correspondence: stefanie.lueth@bfr.bund.de \\ + These authors contributed equally to the work.
}

Received: 29 January 2020; Accepted: 13 March 2020; Published: 14 March 2020

\begin{abstract}
Foodborne infection with Listeria causes potentially life-threatening disease listeriosis. Listeria monocytogenes is widely recognized as the only species of public health concern, and the closely related species Listeria innocua is commonly used by the food industry as an indicator to identify environmental conditions that allow for presence, growth, and persistence of Listeria spp. in general. In our study, we analyze the occurrence of Listeria spp. in a farm-to-fork approach in a poultry production chain in Egypt and identify bacterial entry gates and transmission systems. Prevalence of Listeria innocua at the three production stages (farm, slaughterhouse, food products) ranged from $11 \%$ to $28 \%$. The pathogenic species Listeria monocytogenes was not detected, and Listeria innocua strains under study did not show genetic virulence determinants. However, the close genetic relatedness of Listeria innocua isolates (maximum 63 SNP differences) indicated cross-contamination between all stages from farm to final food product. Based on these results, chicken can be seen as a natural source of Listeria. Last but not least, sanitary measures during production should be reassessed to prevent bacterial contamination from entering the food chain and to consequently prevent human listeriosis infections. For this purpose, surveillance must not be restricted to pathogenic species.
\end{abstract}

Keywords: Listeria innocua; poultry production; food safety; whole-genome sequencing; single nucleotide polymorphism; listeriosis; Listeria monocytogenes

\section{Introduction}

Within the bacterial genus Listeria, Listeria (L.) monocytogenes, the causative agent of listeriosis, is widely recognized as the only species of public health concern. In humans, the clinical picture of listeriosis varies from mild to life-threatening illness with a mortality rate of $20 \%$ to $30 \%$ on average [1]. Severe cases appear mainly in vulnerable populations like pregnant women, newborns, immunocompromised, or older people [2]. The majority of listeriosis cases are foodborne [1]. Although 
closely related to L. monocytogenes (perfect synteny of genome organization), the species L. innocua is considered as non-pathogenic because it lacks the typical virulence genes [3]. However, rare atypical hemolytic L. innocua strains have been described [4,5] and proven to be virulent in in vivo assays using mouse or zebrafish models [6]. Furthermore, L. innocua was isolated from two human patients suffering from fatal sepsis [7] and acute meningitis [8].

Listeria monocytogenes, as well as L. innocua, are widespread in natural environments such as soil, surface water, sewage, or feces of mammals and birds [9,10]. Livestock animals like poultry can be asymptomatic carriers of Listeria spp., and thereby lead to the unnoticed entry of the bacteria into the food chain via contaminated raw animal products [11,12]. Due to its undemanding nature and high adaptability, Listeria is able to persist in food production plants, which may lead to continuous contamination of food through contact with previously contaminated surfaces [13]. Raw animal products are either primarily contaminated or cross-contaminated during food-processing [12]. In this way, Listeria can finally end up in the food chain, posing a health threat for consumers. Detailed knowledge of entry gates and transmission routes is, therefore, indispensable to prevent food contamination and human listeriosis cases.

Because of the high similarity of Listeria species in terms of distribution and adaptability, the transmission path identified for one species is assumed to be transferable to other species. Hence, L. innocua is commonly used by the food industry as an indicator to identify environmental conditions that allow for the presence, growth, and persistence of the relevant human pathogen $L$. monocytogenes $[9,14]$. Using L. innocua as a model for Listeria contamination in general can help to improve surveillance and hygiene measures, which will consequently prevent human infections. However, systematic data on the prevalence of Listeria spp. in poultry slaughterhouses are still limited. In our study, we therefore analyze the occurrence of Listeria spp. in a farm-to-fork approach from the primary production stage to the final food product to reveal bacterial transmission routes. To trace Listeria spp. along the food chain, we applied whole-genome sequencing techniques.

\section{Materials and Methods}

\subsection{Sample Collection}

In total, 210 samples were collected from a single commercial poultry farm with five chicken flocks in separate henhouses and an affiliated slaughterhouse in 2017. The farm and slaughterhouse were located in Dakahlia Governorate, Egypt. The farm owners were asked to sign consent forms after being informed about the aims and goals of our research project and the potential health risks associated with the contamination of food products with Listeria spp. The study followed the ethical guidelines of Mansoura University and was approved by the responsible ethics committee (Code No. R/15).

Samples were collected from three different sources along the food production chain: on the farm, in the slaughterhouse, and from the final chicken products. Two weeks before slaughtering, 25 samples were collected on the chicken farm, all on the same day in November 2017. For soiled litter (containing fresh fecal droppings), poultry feed, drinking water, and the walls of the henhouses, samples were pooled per sampling site $(n=5)$ and per flock $(n=5)$. Five samples (20 g each) were collected from the top few centimeters of soiled litter in different locations of every henhouse (close to drinking troughs and feeding stations, from walls and near the center) and then mixed to form a composite sample of $100 \mathrm{~g}$ for the specific flock. The poultry feed samples were taken from the five different feeding stations of each henhouse. The water samples (20 mL each) were collected from five different drinking troughs of each henhouse and pooled to yield a composite sample of $100 \mathrm{~mL}$. Farm walls were swabbed on five different sites inside each henhouse using a sterile template of $25 \mathrm{~cm}^{2}$ and samples from workers' hands were collected from five individual workers. In the slaughterhouse, 13 cloacal swabs were collected from each of the five flocks just before slaughter $(n=65)$. The birds were randomly selected. In addition, 20 surface swabs (10 from slaughterhouse walls, 5 from tables and 5 from knives) were 
taken during processing. Another 100 samples were taken after slaughter, including swabs from 80 whole carcasses, 10 chicken fillets, and 10 livers.

Hand swabs (palm, between fingers, fingertips, and fingernails) were essentially carried out according to the protocol of Genigeorgis and colleagues [15]. We used buffered peptone water (BPW; Oxoid, Basingstoke, UK) to moisten the cotton swabs and as enrichment broth. Soiled litter, poultry feed, and drinking water were sampled following standard procedures using sterilized spatulas or syringes [16,17]. The samples were homogenized with a stomacher and stored in sterile bags at 4 to $8{ }^{\circ} \mathrm{C}$ until transport to the laboratory. Swabs from surfaces of walls and tables in the slaughterhouse were collected according to the guidelines of the American Public Health Association [18]. Briefly, four $100 \mathrm{~cm}^{2}$ regions of the sampling site were swabbed with sterile sponges moistened with $40 \mathrm{~mL}$ of BPW in several horizontal and vertical movements. The sponges were then transferred to sterile bags containing $160 \mathrm{~mL}$ of BPW to yield a final volume of $200 \mathrm{~mL}$. The farm walls were swabbed using the same technique. The two sides of the butcher's knives were swabbed with BPW-moistened cotton swabs instead of sterile sponges. Cloacal swabs (from the mucosal wall) were collected from living chicken with sterile cotton-tipped swabs pre-moistened in BPW. Swabs from chicken carcasses were collected after evisceration using the method described by McEvoy and colleagues [19]. Briefly, each swab was moistened just before use with $25 \mathrm{~mL}$ of BPW and put into a sterile plastic bag after sampling. Chicken fillet and liver samples ( $25 \mathrm{~g}$ each) were sliced with a sterile scalpel and put into a sterile stomacher bag. All samples were processed under aseptic conditions and then directly sent to the laboratory for further analyses.

\subsection{Listeria Isolation and Identification}

Listeria spp. were isolated and identified as described in the Bacteriological Analytical Manual of the U.S. Food and Drug Administration [20]. For solid samples (poultry feed, chicken fillet, and liver) and water samples, $25 \mathrm{~g}$ or $\mathrm{ml}$ were added to $225 \mathrm{~mL}$ Listeria enrichment broth without antibiotic supplement, pH 8.6 (Oxoid) and homogenized in a stomacher for two minutes. The swab samples were transferred to $10 \mathrm{~mL}$ Listeria enrichment broth. Homogenates of solid samples, water samples, and swabs were incubated at $30^{\circ} \mathrm{C}$ for $4 \mathrm{~h}$. Then, Listeria selective enrichment supplements (Oxoid), including nalidixic acid, cycloheximide, and acriflavine, were added and the broth cultures were incubated at the same temperature for another 24 to $48 \mathrm{~h}$. An inoculation loop of the enriched sample was incubated on Oxford agar (Oxoid) at $35^{\circ} \mathrm{C}$ for 24 to $48 \mathrm{~h}$. At least five colonies showing a black halo characteristic for Listeria spp. were picked, transferred onto tryptic soy agar plates with $0.6 \%$ yeast extract and incubated at $30{ }^{\circ} \mathrm{C}$ for 24 to $48 \mathrm{~h}$. These presumptive Listeria isolates were stored at $-80{ }^{\circ} \mathrm{C}$ in brain heart infusion with $20 \%$ glycerol.

\subsection{Matrix-Assisted Laser Desorption/Ionisation Time-of-Flight (MALDI-TOF) Mass Spectrometry}

After thawing, the bacteria were plated onto sheep blood agar and incubated overnight at $37^{\circ} \mathrm{C}$. Mass spectrometry samples were prepared using the direct smear method [21]. Species identification was performed using the MALDI Biotyper ${ }^{\circledR}$ Subtyping Module (Bruker Daltonik, Bremen, Germany) according to the manufacturer's instructions.

\subsection{Genomic DNA Extraction and Next Generation Sequencing}

All strains identified as Listeria spp. by MALDI-TOF MS were again grown on sheep blood agar overnight at $37^{\circ} \mathrm{C}$. Bacterial cells were harvested and lysed following the Pulse Net standardized laboratory protocol for whole-genome sequencing of Gram-positive bacteria (https://www.cdc.gov/ pulsenet/pdf/pnl32-miseq-nextera-xt.pdf). We extracted DNA with the QIAamp DNA Mini Kit (Qiagen, Hilden, Germany) according to the manufacturer's instructions.

Sequencing libraries were constructed using the Nextera XT Sample Preparation Kit (Illumina, Inc., San Diego, CA, USA). Sequencing was performed in paired-end mode with $2 \times 300$ bp reads on the Illumina MiSeq sequencer using the MiSeq Reagent v3 600-cycle Kit (Illumina). 


\subsubsection{Multilocus Sequence Typing (MLST)}

Multilocus sequences types (ST) and clonal complexes (CC) were determined according to the scheme available at https://bigsdb.pasteur.fr/listeria/listeria.html.

\subsubsection{Single Nucleotide Polymorphism (SNP) Analysis}

Sequences were trimmed with Trimmomatic version 0.36 [22] using default parameters. Trimmed reads were mapped to the closed reference genome of L. innocua (NC_003212.1) in BioNumerics version 7.6 (Applied Maths, Gent, Belgium), followed by SNP calling. Strict SNP filtering with software default parameters was applied.

\subsubsection{In Silico Screening for Virulence Factors}

Trimmed reads were de novo assembled with SPAdes version 3.11.1 [23]. Assembled genomes were used for virulence gene screening with ABRicate version 0.8 [24] using the Virulence Factor Database (VFDB) (2597 sequences, [25], last updated 9 July 2019). The L. monocytogenes reference strain EGDe (NC_003210.1) was included in the screening as a representative for a pathogenic strain. A cut-off of at least $80 \%$ gene identity was applied for gene presence.

\subsubsection{Data Storage}

The data for this study have been deposited in the European Nucleotide Archive (ENA) at EMBL-EBI under accession number PRJEB36384.

\section{Results}

\subsection{Prevalence of Listeria spp. along the Poultry Production Chain}

Listeria innocua was the only Listeria species identified by MALDI-TOF MS and was isolated from $17 \%(36 / 210)$ of the samples along the poultry production chain (Table 1). The prevalence of L. innocua on the farm level was $28 \%(7 / 25)$. Listeria innocua was found in $100 \%(5 / 5)$ of the swabs from farm walls and in $20 \%(1 / 5)$ of the samples from soiled litter or poultry feed. Both workers' hands and drinking water tested negative for L. innocua. A total of 9 out of 85 samples (11\%) collected in the slaughterhouse revealed L. innocua. Tables and abattoir walls were contaminated, with $40 \%(2 / 5)$ and $20 \%(2 / 10)$ positive swabs, respectively, whereas knives were tested negative. Five out of $85(7 \%)$ cloacal swabs taken from three of the five chicken flocks tested positive. Finally, L. innocua was identified in $20 \%$ (20/100) of the food samples, with $11 \%(9 / 80)$ of the carcasses, $50 \%(5 / 10)$ of raw chicken fillets, and $60 \%(6 / 10)$ of the liver samples being positive.

Table 1. Occurrence of Listeria innocua along the poultry production chain

\begin{tabular}{cccc}
\hline Source of Sample & Number of Samples Tested & $\begin{array}{c}\text { Number of Positive } \\
\text { Samples }\end{array}$ & \% of Positive Samples \\
\hline Chicken farm & $\mathbf{2 5}^{\mathbf{1}}$ & $\mathbf{7}$ & $\mathbf{2 8}$ \\
soiled litter & 5 & 1 & 20 \\
drinking water & 5 & 0 & 0 \\
poultry feed & 5 & 1 & 20 \\
farm wall & 5 & 5 & 100 \\
workers' hands & $5^{2}$ & 0 & 0 \\
Slaughterhouse & $\mathbf{8 5}$ & $\mathbf{9}$ & 8 \\
chicken cloaca & 65 & 5 & 20 \\
slaughterhouse wall & 10 & 2 & 0 \\
knife & 5 & 0 & 40 \\
table & 5 & 2 & \\
\hline
\end{tabular}


Table 1. Cont.

\begin{tabular}{cccc}
\hline Source of Sample & Number of Samples Tested & $\begin{array}{c}\text { Number of Positive } \\
\text { Samples }\end{array}$ & \% of Positive Samples \\
\hline Food product & $\mathbf{1 0 0}^{\mathbf{2}}$ & $\mathbf{2 0}$ & $\mathbf{2 0}$ \\
carcass & 80 & 9 & 11 \\
chicken fillet & 10 & 5 & 50 \\
chicken liver & 10 & 6 & 60 \\
\hline total & $\mathbf{2 1 0}$ & $\mathbf{3 6}$ & $\mathbf{1 7}$ \\
\hline & ${ }^{1}$ pooled samples; ${ }^{2}$ individual samples.
\end{tabular}

\subsection{Genomic Analysis}

Whole-genome sequencing of the 36 Listeria isolates confirmed the MALDI-TOF MS results and clearly assigned them to the species L. innocua ( $94 \%$ to $100 \%$ of reads mapping to the L. innocua Clip11262 complete genome, NC_003212.1). All isolates belonged to the same L. innocua-specific MLST ST 530 (corresponding to CC ST530, Lineage: L. innocua). Sequencing coverage ranged between 43and 132-fold (median 78). The 36 isolates showed 0 to 63 SNPs difference (median 41) and formed four distinct clusters of isolates differing by no more than $0,3,5$, or 10 SNPs (Figure 1). Clusters were not restricted to a specific sampling site or sampling stage except for one cluster (no. 4), which included two isolates from carcasses (Figures 1 and 2).

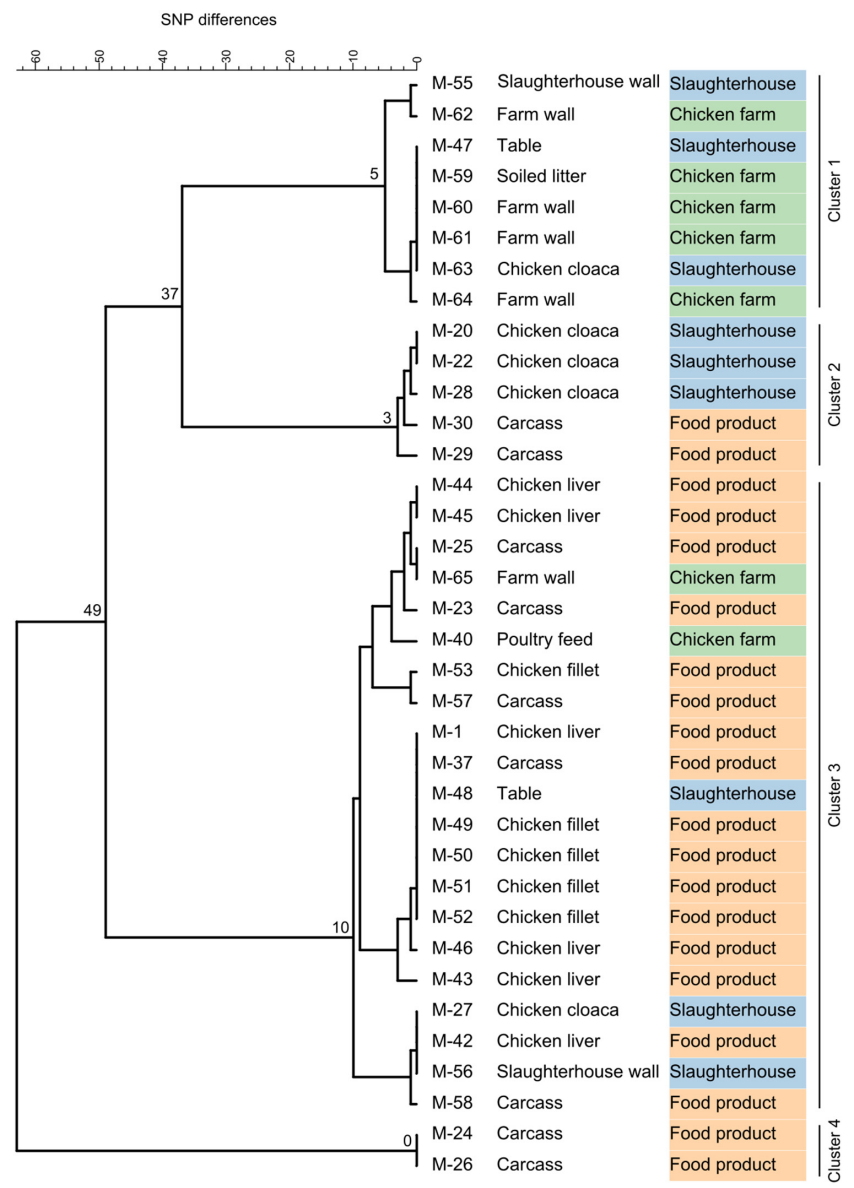

Figure 1. Complete linkage tree summarizing SNP analysis results from 36 Listeria innocua isolates. Node labels indicate the maximum SNP difference in the branch. Isolates fell into four distinct clusters differing by no more than $5,3,10$, or 0 SNPs. Clusters were not restricted to a specific sampling site (first column) or sampling stage (second column) except for Cluster 4. 


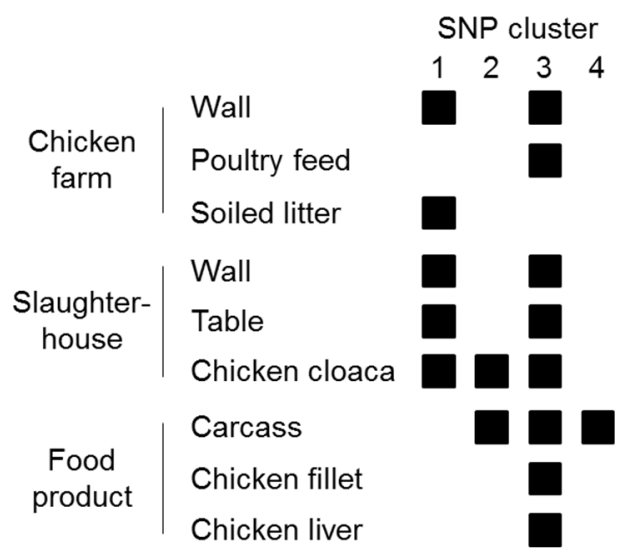

Figure 2. Visualization of contaminated sites and presumable transmission routes based on SNP clusters. Cross-contamination is likely to have happened between all production stages.

The L. innocua isolates under study harbored 12 to 13 L. monocytogenes virulence genes (Figure 3). However, the Listeria pathogenicity island LIPI-1 and internalins, especially inlA, which are genetic determinants for virulence in either atypical hemolytic $L$. innocua strains or in the pathogenic species $L$. monocytogenes [6], were only found in the sequence of the L. monocytogenes reference strain EGDe and were missing in all L. innocua isolates.

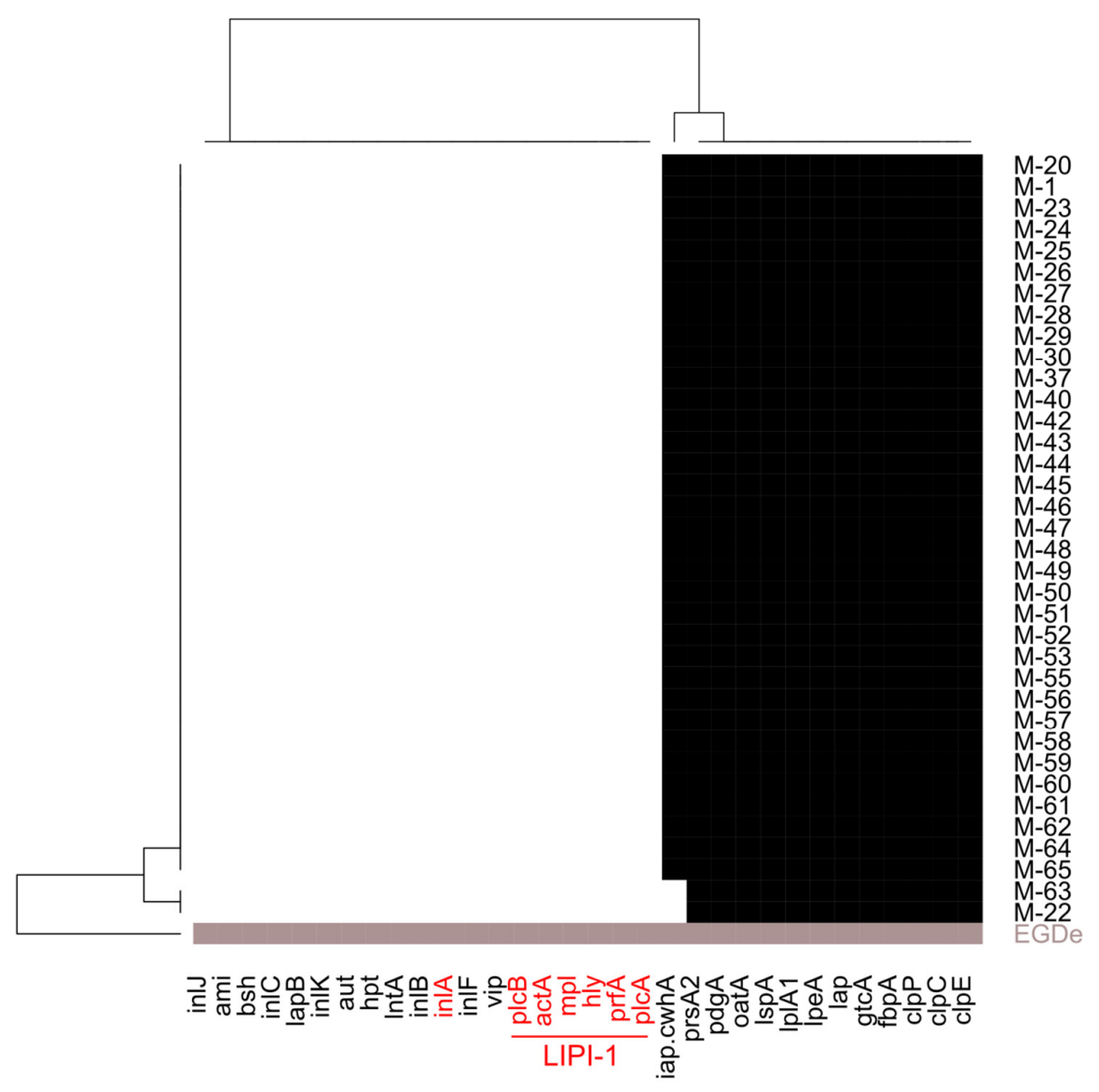

Figure 3. Heatmap of in silico detected virulence genes in the Listeria (L.) innocua study population (black: gene present; white: gene absent) compared to the L. monocytogenes reference strain EGDe (grey: gene present). None of the L. innocua study isolates contained virulence factors like inlA or the Listeria pathogenicity island 1 (LIPI-1; in red) that are found in atypical hemolytic L. innocua [6]. 


\section{Discussion}

At the three stages of the poultry production chain investigated (farm, slaughterhouse, food products), the prevalence of L. innocua ranged from $11 \%$ to $28 \%$.

As we only looked into one specific farm-to-fork continuum (one farm, one slaughterhouse) in our study, the prevalences found at the various production stages cannot necessarily be generalized. However, our prevalence rates on farm level were in agreement with a previous study on a poultry farm in Egypt [26] where L. innocua was found in 20\% (4/20) of samples from poultry feed but not in drinking water $(0 / 20)$. However, L. innocua was more prevalent in soiled litter than in our study (35\% (28/80) vs. $20 \%(1 / 5))$. The observed difference could be explained either by the very different sample sizes or by variable efficiency of biosecurity practices on the farms. In our study, the overall prevalence of L. innocua on the farm was $28 \%$. The prevalence reported for Listeria spp. (especially L. monocytogenes and L. innocua) on farms in various countries varied widely, ranging from $1.4 \%$ to $53 \%[9,27-31]$. Accordingly, the detection rates for Listeria spp. in soiled litter $(10 \%-53 \%)$, poultry feed $(70 \%)$, drinking water $(10 \%)$, soil $(30 \%)$, and grass $(6 \%-43 \%)$ were quite variable. In accordance with our results, L. innocua was the predominant species, representing up to $78 \%$ of the Listeria isolates.

The slaughterhouse prevalence of $L$. innocua in our study was $11 \%$. The highest rate was found in swabs collected from tables $(40 \%, 2 / 5)$, indicating that hygiene measures were not always properly applied to remove surface contamination. Lower contamination rates were found on the walls $(20 \%$, $2 / 10)$ and in cloacal swabs $(8 \%, 5 / 65)$. A positive cloacal swab indicates intestinal colonization of the chicken. Hence, the positive rate of cloacal swabs is actually an indicator of the prevalence of carrier animals in the livestock population that form the basis for zoonotic entry of Listeria into the food chain. In our study, according to the microbiological results from cloacal swabs, three of the five chicken flocks tested were carriers of L. innocua. A lower detection rate $(2 \%, 7 / 400)$ for L. innocua in cloacal swabs from laying hens was reported from Bavaria, Germany [28]. In the suburbs of Tokyo, Listeria spp. were found in $5 \%$ of 150 fresh fecal droppings collected on four chicken farms [32]. In a Danish study, Listeria spp. could not be isolated at all from 50 cloacal swabs taken at the abattoir of 71 broiler flocks [27]. Obviously, there are major differences in the Listeria prevalence rates in chicken livestock among countries.

In our dataset, the overall occurrence of $L$. innocua in raw poultry meat and chicken products was $20 \%(20 / 100)$. Higher prevalence rates for L. innocua in raw poultry meat were reported from Spain $(66 \%)$, Turkey (58\%), Italy (40\%), Jordan (50\%), and Egypt (31\%) [26,33-36] while lower rates were reported from Morocco (14\%) and Iran (19\%) [37,38]. Contamination of raw animal products may occur after slaughter or during food processing. Major influencing factors are the primary prevalence of the pathogen in the livestock population, on the one hand, and hygiene measures such as surface disinfection during processing, on the other hand.

To get detailed insights into possible transmission routes along the poultry production chain, we analyzed single nucleotide polymorphisms of L. innocua isolates at various stages of production (Figure 1). Based on the fact that natural mutation rates in the genus Listeria are low, a very low number of SNP differences between two or more strains are commonly used as an indicator of their epidemiological relatedness $[39,40]$. The guiding assumption is that a small genetic difference between strains indicates a common origin. In our study, based on the high genetic relatedness of L. innocua isolates from different sampling sites from farm to final food product, transfer between all stages of the production chain appears very likely. Although no directional information can be extracted from the genetic data alone, accompanying metadata can be used to speculate about causal relationships between contaminated sites and transmission routes (Figure 2). For instance, zero SNP differences were identified between L. innocua isolates from chicken liver, fillet, carcass, and a slaughterhouse table (Figure 1; within Cluster 3). Presumably, the same bacterial strain has been transferred between all these sampling sites, indicating cross-contamination during the processing of the slaughtered chicken. Of positive note is the fact that all samples from knives and hands were negative for Listeria spp., indicating that hygienic measures are already successfully applied to a certain extent, although the 
relatively low number of samples taken from both sites may qualify this statement. However, knowing that there is likely entry of L. innocua into the food processing plant from the farm, other surfaces should be under proper internal monitoring as well. For example, the same strain (zero SNPs difference) could be found on a table in the slaughterhouse and in cloacal swabs, as well as on farm walls and in the soiled litter (Figure 1; within Cluster 1). Consequently, bacterial contamination on the farm has reached the processing level, thereby posing a risk for further cross-contamination during processing steps performed on the table. Since contamination with L. innocua was already present on the farm, the food operator should reassess the sanitary measures applied and the way how chickens are introduced into the processing stage to prevent contamination from entering the production chain. If no reasonable measures are taken, Listeria can establish persistence in food processing plants, which may form the basis for repeated re-contamination $[13,41,42]$.

Listeria innocua strains isolated in our study did not show any genetic virulence determinants needed for human or animal infection, as described for L. monocytogenes strains and rare hemolytic L. innocua strains [6]. In addition, all isolates were non-hemolytic on sheep blood agar. Therefore, it is highly unlikely that they would have been able to cause human infection. Furthermore, the pathogenic species L. monocytogenes was not detected. However, as previously mentioned, the Oxford medium used in our study does not allow for a distinction between colonies of different Listeria species [43]. A chromogenic agar, as described in ISO 11290:1:2017, would have been able to improve L. monocytogenes detection but it was not available in Egypt at the time of the study. Therefore, presumptive Listeria spp. colonies were randomly selected and L. monocytogenes isolates could have been missed. Additionally, L. innocua can produce a bacteriocin-like substance against L. monocytogenes and usually grows faster in enrichment broth, leading to an underestimation of the prevalence of $L$. monocytogenes $[27,43]$.

While several studies from Egypt have reported frequent contamination of foodstuffs such as meat and dairy products with different Listeria spp. [26,44-47] such food has not yet been associated with documented outbreaks of listeriosis. A major reason for this is probably the lack of a surveillance system for human listeriosis in Egypt and hence underreporting of cases. As a result, the real public health burden caused by Listeria contamination throughout the food chain is very difficult to assess. Further close monitoring of slaughtering and company hygiene practices and their continuous adjustment and improvement will help to gain insights into the risks emerging from different food sources and will make an essential contribution to prevent listeriosis cases.

\section{Conclusions}

Our study did not reveal any L. monocytogenes contamination, but L. innocua existed throughout the entire chicken meat processing chain from stable to table. Given that L. innocua was not only isolated from environmental samples on the farm and in the slaughterhouse but also from cloacal swabs, chicken can be seen as a natural source of L. innocua. The presence of any non-pathogenic Listeria spp. like L. innocua in processing lines and foodstuffs is a good indicator for poor hygienic conditions and serves as an alarming sign for the need to implement appropriate hygiene practices. Through knowing and eliminating risk factors, contamination of poultry food products with the pathogenic species L. monocytogenes can be effectively prevented.

Author Contributions: Conceptualization, M.G., S.L., and S.A.D.; Data curation, S.L.; Formal analysis, M.G. and S.L.; Funding acquisition, S.K. and S.A.D.; Investigation, M.G., M.E.-A., A.Z., F.E.-G., and M.E.; Project administration, M.G.; Resources, S.K. and S.A.D.; Supervision, M.G. and S.A.D.; Visualization, S.L.; Writing — original draft, M.G. and S.L.; Writing—review and editing, M.E.-A., S.K., and S.A.D. All authors have read and agreed to the published version of the manuscript.

Funding: This research was funded by the German Federal Institute for Risk Assessment (grant no. 1322-668).

Acknowledgments: We would like to thank Anna-Louisa Hauffe and Marett Splett for their excellent technical assistance throughout the study. 
Conflicts of Interest: The funders had no role in the design of the study; in the collection, analyses, or interpretation of data; in the writing of the manuscript; or in the decision to publish the results.

\section{References}

1. Swaminathan, B.; Gerner-Smidt, P. The epidemiology of human listeriosis. Microbes Infect. 2007, 9, $1236-1243$. [CrossRef]

2. Schuchat, A.; Swaminathan, B.; Broome, C.V. Epidemiology of human listeriosis. Clin. Microbiol. Rev. 1991, 4, 169-183. [CrossRef]

3. Buchrieser, C.; Rusniok, C.; Consortium, L.; Kunst, F.; Cossart, P.; Glaser, P. Comparison of the genome sequences of Listeria monocytogenes and Listeria innocua: Clues for evolution and pathogenicity. FEMS Immunol. Med. Microbiol. 2003, 35, 207-213. [CrossRef]

4. Johnson, J.; Jinneman, K.; Stelma, G.; Smith, B.; Lye, D.; Messer, J.; Ulaszek, J.; Evsen, L.; Gendel, S.; Bennett, R. Natural atypical Listeria innocua strains with Listeria monocytogenes pathogenicity island 1 genes. Appl. Environ. Microbiol. 2004, 70, 4256-4266. [CrossRef] [PubMed]

5. Moreno, L.Z.; Paixao, R.; Gobbi, D.D.; Raimundo, D.C.; Ferreira, T.P.; Hofer, E.; Matte, M.H.; Moreno, A.M. Characterization of atypical Listeria innocua isolated from swine slaughterhouses and meat markets. Res. Microbiol. 2012, 163, 268-271. [CrossRef] [PubMed]

6. Moura, A.; Disson, O.; Lavina, M.; Thouvenot, P.; Huang, L.; Leclercq, A.; Fredriksson-Ahomaa, M.; Eshwar, A.K.; Stephan, R.; Lecuit, M. Atypical hemolytic Listeria innocua are virulent, albeit less than Listeria monocytogenes. Infect. Immun. 2019. [CrossRef] [PubMed]

7. Perrin, M.; Bemer, M.; Delamare, C. Fatal case of Listeria innocua bacteremia. J. Clin. Microbiol. 2003, 41, 5308-5309. [CrossRef] [PubMed]

8. Favaro, M.; Sarmati, L.; Sancesario, G.; Fontana, C. First case of Listeria innocua meningitis in a patient on steroids and eternecept. JMM Case Rep. 2014, 1, e003103. [CrossRef]

9. Milillo, S.R.; Friedly, E.C.; Saldivar, J.C.; Muthaiyan, A.; O’Bryan, C.; Crandall, P.G.; Johnson, M.G.; Ricke, S.C. A Review of the Ecology, Genomics, and Stress Response of Listeria innocua and Listeria monocytogenes. Crit. Rev. Food Sci. Nutr. 2012, 52, 712-725. [CrossRef]

10. Sauders, B.D.; Overdevest, J.; Fortes, E.; Windham, K.; Schukken, Y.; Lembo, A.; Wiedmann, M. Diversity of Listeria species in urban and natural environments. Appl. Environ. Microbiol. 2012, 78, 4420-4433. [CrossRef]

11. Mbata, T.I. Poultry meat pathogens and its control. Internet J. Food Saf. 2005, 7, 20-28.

12. Lakicevic, B.; Nastasijevic, I.; Raseta, M. Sources of Listeria monocytogenes contamination in retail establishments. Procedia Food Sci. 2015, 5, 160-163. [CrossRef]

13. Carpentier, B.; Cerf, O. Persistence of Listeria monocytogenes in food industry equipment and premises. Int. J. Food Microbiol. 2011, 145, 1-8. [CrossRef] [PubMed]

14. Orsi, R.H.; Wiedmann, M. Characteristics and distribution of Listeria spp., including Listeria species newly described since 2009. Appl. Microbiol. Biotechnol. 2016, 100, 5273-5287. [CrossRef]

15. Genigeorgis, C.A.; Dutulescu, D.; Garayzabal, J.F. Prevalence of Listeria spp. in poultry meat at the supermarket and slaughterhouse level. J. Food Prot. 1989, 52, 618-624. [CrossRef]

16. Terzich, M.; Pope, M.J.; Cherry, T.E.; Hollinger, J. Survey of pathogens in poultry litter in the United States. J. Appl. Poult. Res. 2000, 9, 287-291. [CrossRef]

17. American Public Health Association. Standard methods for the examination of water and wastewater, 21st ed.; Am. Public Health Assoc. (APHA): Washington, DC, USA, 2005.

18. American Public Health Association. Compendium of Methods for the Microbial Examination of Foods; Vanderzant, C., Splittstoesser, D.F., Eds.; APHA: Washington, DC, USA, 1992.

19. McEvoy, J.; Nde, C.; Sherwood, J.; Logue, C. An evaluation of sampling methods for the detection of Escherichia coli and Salmonella on turkey carcasses. J. Food Prot. 2005, 68, 34-39. [CrossRef]

20. Hitchins, A.D.; Jinneman, K.; Chen, Y. BAM: Detection and Enumeration of Listeria monocytogenes. Bacteriol. Anal. Man. 2016.

21. Freiwald, A.; Sauer, S. Phylogenetic classification and identification of bacteria by mass spectrometry. Nat. Protoc. 2009, 4, 732. [CrossRef]

22. Bolger, A.M.; Lohse, M.; Usadel, B. Trimmomatic: A flexible trimmer for Illumina sequence data. Bioinformatics 2014, 30, 2114-2120. [CrossRef] 
23. Bankevich, A.; Nurk, S.; Antipov, D.; Gurevich, A.A.; Dvorkin, M.; Kulikov, A.S.; Lesin, V.M.; Nikolenko, S.I.; Pham, S.; Prjibelski, A.D.; et al. SPAdes: A New Genome Assembly Algorithm and Its Applications to Single-Cell Sequencing. J. Comput. Biol. 2012, 19, 455-477. [CrossRef] [PubMed]

24. Seemann, T. Abricate-Mass Screening of Contigs for Antimicrobial and Virulence Genes. Available online: https://github.com/tseemann/abricate (accessed on 9 August 2019).

25. Liu, B.; Zheng, D.; Jin, Q.; Chen, L.; Yang, J. VFDB 2019: A comparative pathogenomic platform with an interactive web interface. Nucleic Acids Res. 2019, 47, D687-D692. [CrossRef] [PubMed]

26. Dahshan, H.; Merwad, A.; Mohamed, T.S. Listeria species in broiler poultry farms: Potential public health hazards. J. Microbiol. Biotechnol. 2016, 26, 1551-1556. [CrossRef] [PubMed]

27. Petersen, L.; Madsen, M. Listeria spp. in broiler flocks: Recovery rates and species distribution investigated by conventional culture and the EiaFoss method. Int. J. Food Microbiol. 2000, 58, 113-116. [CrossRef]

28. Schwaiger, K.; Schmied, E.M.; Bauer, J. Comparative analysis on antibiotic resistance characteristics of Listeria spp. and Enterococcus spp. isolated from laying hens and eggs in conventional and organic keeping systems in Bavaria, Germany. Zoonoses Public Health 2010, 57, 171-180. [CrossRef]

29. Jones, D.; Anderson, K.; Guard, J. Prevalence of coliforms, Salmonella, Listeria, and Campylobacter associated with eggs and the environment of conventional cage and free-range egg production. Poult. Sci. 2012, 91, 1195-1202. [CrossRef]

30. Milillo, S.; Stout, J.; Hanning, I.; Clement, A.; Fortes, E.; Den Bakker, H.; Wiedmann, M.; Ricke, S. Listeria monocytogenes and hemolytic Listeria innocua in poultry. Poult. Sci. 2012, 91, 2158-2163. [CrossRef]

31. Dhama, K.; Verma, A.K.; Rajagunalan, S.; Kumar, A.; Tiwari, R.; Chakraborty, S.; Kumar, R. Listeria monocytogenes infection in poultry and its public health importance with special reference to food borne zoonoses. Pak. J. Biol. Sci. 2013, 16, 301-308. [CrossRef]

32. Iida, T.; Kanzaki, M.; Maruyama, T.; Inoue, S.; Kaneuchi, C. Prevalence of Listeria monocytogenes in intestinal contents of healthy animals in Japan. J. Vet. Med. Sci. 1991, 53, 873-875. [CrossRef]

33. Capita, R.; Alonso-Calleja, C.; Moreno, B.; Garcia-Fernández, M.A.C. Occurrence of Listeria species in retail poultry meat and comparison of a cultural/immunoassay for their detection. Int. J. Food Microbiol. 2001, 65, 75-82. [CrossRef]

34. Yücel, N.; Citak, S.; Önder, M. Prevalence and antibiotic resistance of Listeria species in meat products in Ankara, Turkey. Food Microbiol. 2005, 22, 241-245. [CrossRef]

35. Pesavento, G.; Ducci, B.; Nieri, D.; Comodo, N.; Nostro, A.L. Prevalence and antibiotic susceptibility of Listeria spp. isolated from raw meat and retail foods. Food Control. 2010, 21, 708-713. [CrossRef]

36. Osaili, T.M.; Alaboudi, A.R.; Nesiar, E.A. Prevalence of Listeria spp. and antibiotic susceptibility of Listeria monocytogenes isolated from raw chicken and ready-to-eat chicken products in Jordan. Food Control. 2011, 22, 586-590. [CrossRef]

37. Amajoud, N.; Leclercq, A.; Soriano, J.M.; Bracq-Dieye, H.; El Maadoudi, M.; Senhaji, N.S.; Kounnoun, A.; Moura, A.; Lecuit, M.; Abrini, J. Prevalence of Listeria spp. and characterization of Listeria monocytogenes isolated from food products in Tetouan, Morocco. Food Control. 2018, 84, 436-441. [CrossRef]

38. Hamidiyan, N.; Salehi-Abargouei, A.; Rezaei, Z.; Dehghani-Tafti, R.; Akrami-Mohajeri, F. The prevalence of Listeria spp. food contamination in Iran: A systematic review and meta-analysis. Food Res. Int. 2018, 107, 437-450. [CrossRef] [PubMed]

39. Orsi, R.H.; Borowsky, M.L.; Lauer, P.; Young, S.K.; Nusbaum, C.; Galagan, J.E.; Birren, B.W.; Ivy, R.A.; Sun, Q.; Graves, L.M. Short-term genome evolution of Listeria monocytogenes in a non-controlled environment. BMC Genom. 2008, 9, 539. [CrossRef]

40. Pightling, A.W.; Pettengill, J.B.; Luo, Y.; Baugher, J.D.; Rand, H.; Strain, E. Interpreting Whole-Genome Sequence Analyses of Foodborne Bacteria for Regulatory Applications and Outbreak Investigations. Front. Microbiol. 2018, 9, 1482. [CrossRef]

41. Møretrø, T.; Langsrud, S. Listeria monocytogenes: Biofilm formation and persistence in food-processing environments. Biofilms 2004, 1, 107-121. [CrossRef]

42. Ferreira, V.; Wiedmann, M.; Teixeira, P.; Stasiewicz, M.J. Listeria monocytogenes persistence in food-associated environments: Epidemiology, strain characteristics, and implications for public health. J. Food Prot. 2014, 77, 150-170. [CrossRef]

43. Azevedo, I.; Regalo, M.; Mena, C.; Almeida, G.; Carneiro, L.; Teixeira, P.; Hogg, T.; Gibbs, P.A. Incidence of Listeria spp. in domestic refrigerators in Portugal. Food Control. 2005, 16, 121-124. [CrossRef] 
44. Ahmed, A.M.; El-Atti, N.M.A. Existence of Listeria species in broiler carcasses with an attempt to control Listeria monocytogenes using trisodium phosphate. Afr. J. Food Sci. 2010, 4, 046-051.

45. El-Malek, A.M.A.; Ali, S.F.H.; Hassanein, R.; Mohamed, M.A.; Elsayh, K.I. Occurrence of Listeria species in meat, chicken products and human stools in Assiut city, Egypt with PCR use for rapid identification of Listeria monocytogenes. Vet. World 2010, 3, 353. [CrossRef]

46. Ismaiel, A.A.-R.; Ali, A.E.-S.; Enan, G. Incidence of Listeria in Egyptian meat and dairy samples. Food Sci. Biotechnol. 2014, 23, 179-185. [CrossRef]

47. Osman, K.M.; Samir, A.; Abo-Shama, U.H.; Mohamed, E.H.; Orabi, A.; Zolnikov, T. Determination of virulence and antibiotic resistance pattern of biofilm producing Listeria species isolated from retail raw milk. BMC Microbiol. 2016, 16, 263. [CrossRef]

(C) 2020 by the authors. Licensee MDPI, Basel, Switzerland. This article is an open access article distributed under the terms and conditions of the Creative Commons Attribution (CC BY) license (http://creativecommons.org/licenses/by/4.0/). 